\title{
How Far Has the World Come?
}

Constitutions state the rules of the game for each of our countries. They represent agreements between governments and their people, and commitments to respect, protect, and fulfill fundamental rights. How far have we come as humanity in ensuring that everyone has the right to live, learn, love, and work fully?

In nearly every area, there has been substantial progress in equal rights since 1970. While barely over half of current constitutions (54\%) adopted before 1970 explicitly protect women's equal rights, $100 \%$ of those adopted in 2010-17 do so. Similarly, for race/ethnicity, just $49 \%$ of constitutions adopted before 1970 include explicit protections, compared to $79 \%$ of those adopted in 2010-17. Looking at religion, only $56 \%$ adopted before 1970 clearly establish equal rights; between 2010 and $2017,92 \%$ do so. For socioeconomic status (SES), the share with explicit protections jumped from $34 \%$ adopted before 1970 to $83 \%$ adopted in 2010-17. And while progress on disability rights has been more recent, the increase in protections in just the past few decades has been similarly dramatic: only $9 \%$ of constitutions adopted in 1980-89 protect equal rights on the basis of disability, compared to $71 \%$ adopted in 2010-17. However, rights continue to lag far behind for two groups: people living in countries where they are not citizens, and people whose sexual orientation or gender identity places them in the minority.

Moreover, commitments to provide every citizen with the opportunity for an education, and access to the healthcare and healthy environments needed to survive and thrive, have dramatically increased. All constitutions adopted since 2010 
take some approach to protecting the right to education, compared to just twothirds of current constitutions adopted before 1970. Further, while less than half of constitutions adopted before 1970 guarantee free primary education, two-thirds of those adopted in 2010-17 do so. Similarly, just one-third of constitutions adopted before 1970 take any approach to health, whereas all those adopted in 2010-17 include the right to health, public health, and/or medical care.

Despite remarkable progress over the past six decades, substantial work remains to be done. In the following section, we summarize key findings of where we are as a global community, as well as priorities for action.

\section{SUMMARY OF FINDINGS: EQUAL RIGHTS}

\section{Historic Exclusion and Persisting Inequalities: Advancing Equal Rights on the Basis of Race and Ethnicity}

As of $2017,76 \%$ of constitutions guarantee equal rights before the law regardless of race/ethnicity. At the beginning of the constitutional era, nothing could have been further from the case. Through its infamous "Three-Fifths Compromise," the U.S. Constitution specified that slaves were worth "three fifths of all other Persons" for purposes of determining states' representation in Congress. ${ }^{1}$ Beyond sanctioning slavery as an institution, this and other legal provisions symbolized the dehumanization of African Americans and Native Americans that characterized centuries of U.S. history.

Over the past 50 years, the share of constitutions guaranteeing equal rights and prohibiting racial discrimination has gradually increased: $49 \%$ of current constitutions adopted before 1970, $78 \%$ adopted in the 1970s, $73 \%$ adopted in the 1980 , $88 \%$ adopted in the 1990 s, $89 \%$ adopted in the 2000 , and $79 \%$ adopted in $2010-17$ explicitly protect equal rights regardless of race/ethnicity.

However, far fewer protect against subtler forms of discrimination. Throughout history, governments have enacted laws and policies that are not racially discriminatory on their face, but have discriminatory impacts. In the United States, for instance, post-Civil War poll taxes disproportionately excluded African Americans from voting; it is estimated that Georgia's poll tax, enacted in 1871 , reduced voting overall by $16-28 \%$, and voting by black citizens by half. ${ }^{2}$ More recently, some evidence suggests that strict voter identification laws are having similar effects. ${ }^{3}$ Private employers often engage in indirect discrimination as well. For example, a job posting requiring a "native English speaker" would indirectly discriminate against a fully bilingual candidate whose first language was not English. This example also illustrates how language discrimination often intersects with discrimination on the basis of race/ ethnicity, national origin, or migration status. Yet just $45 \%$ of constitutions protect against language discrimination, while a mere 5\% protect against indirect racial/ethnic discrimination. 
Racial/ethnic discrimination is also not solvable without addressing discrimination based on SES. Across countries, centuries of racial/ethnic segregation, bans, barriers, and discrimination have left racial/ethnic minorities and marginalized groups with a far greater likelihood of living in poverty than majority populations. In Australia, $19.3 \%$ of indigenous households fall below the poverty line, compared to $12.4 \%$ of other Australians. ${ }^{4}$ In the United States, poverty rates among the black and Hispanic populations are $22 \%$ and $20 \%$, respectively, compared to $9 \%$ among white Americans. ${ }^{5}$

Moreover, studies have demonstrated that while there is independent discrimination based on race/ethnicity and social class, simultaneous discrimination places many people in greater jeopardy. As one simple example, a U.S. study involved responding to job openings by submitting CVs, identical but for applicant names and addresses, to see who would be invited to interview. Applicants with names that were more prevalent among African Americans were far less likely to receive invitations; their odds decreased even further when their addresses indicated lowincome neighborhoods. ${ }^{6}$ The same occurred in India where names on the CVs represented both caste or social class and the likelihood of darker skin color. ${ }^{7}$ Yet, while $76 \%$ of constitutions guarantee equal rights across race/ethnicity, only $59 \%$ protect against class-based discrimination.

In nearly one-quarter of countries, the first step must be enacting an explicit protection of equal rights on the basis of race/ethnicity; a constitutional equal rights guarantee provides a foundation for challenging a wide range of discriminatory laws and practices. Moreover, a clear protection of equal rights for people of all racial/ethnic backgrounds represents an important rebuke of the history of constitutions that excluded racial/ethnic minorities from full citizenship.

For the 146 countries that already protect equal rights regardless of race/ethnicity, addressing the ways that racial/ethnic discrimination often overlaps and intersects with class discrimination would strengthen these approaches. Likewise, prohibiting indirect discrimination would allow for the identification of policies and practices that disproportionately affect specific groups, and various countries' courts have shown it is feasible to evaluate these policies with nuance. Currently, however, just nine countries address indirect racial/ethnic discrimination. Finally, just a handful of countries explicitly address segregation. While it is now broadly recognized that "separate but equal" is not equal at all, the legacy of racial/ethnic discrimination in the law, including its impacts on economic inequality, has perpetuated segregation in practice. Including a commitment to desegregation in constitutions could spur governments to take more proactive steps.

\section{Why Addressing Gender Equality Is Foundational}

The history of legal discrimination based on gender is millennia old. Throughout much of recorded history, women have been banned from voting and holding office, owning property, and performing many jobs. Yet equal rights for women 
in constitutions have dramatically transformed over the past 50 years. Among constitutions enacted before the 1970s-the decade of the adoption of the Convention on the Elimination of All Forms of Discrimination Against Women (CEDAW) - just 54\% guarantee equal rights regardless of sex; among constitutions adopted each decade after the 1970s, at least nine out of ten consistently include these protections.

And yet gender inequality remains profound around the world, with high costs to all. ${ }^{8}$ While countries nearly universally guarantee equal civil and political rights for women, a huge gap lies in addressing economic equality. Women's wages still fall far behind men's, with women globally earning $24 \%$ less than men. ${ }^{9}$ The World Economic Forum's 2017 Global Gender Gap report showed that the economic gap between men and women had in fact widened rather than narrowed over the preceding 12 months, and that closing it would take 217 more years. ${ }^{10}$

These gaps are due to both discrimination in workplaces and disadvantages that surface much earlier in life. Despite progress, girls remain less likely to get an education: across low-income countries, just 66 girls finish secondary school for every 100 boys. ${ }^{11}$ Yet when education is free and discrimination banned, this gap closes.

Clearly, discrimination and unnecessary obstacles deeply diminish girls' and women's hopes, opportunities, and life experiences. Equally clearly, research reveals profound costs to whole economies. Strengthening women's legal rights has been associated with higher labor force participation by women, which in turn boosts national GDP. ${ }^{12}$ Indeed, increasing women's labor force participation to its full potential would boost annual GDP in 2025 by $\$ 2.9$ trillion in India and $\$ 4.2$ trillion in China. ${ }^{13}$ Even smaller increases would be transformative. For example, if women's labor force participation across the United States matched that of the highest-performing U.S. state, national GDP would rise \$2.1 trillion over the same time period. ${ }^{14}$ Similarly, according to the International Labour Organization, closing the gender gap in labor force participation by just $25 \%$ by 2025 could increase global GDP by $\$ 5.3$ trillion. ${ }^{15}$

Moreover, the extent to which countries address whether differences between men and women that are irrelevant to the job lead to exclusion in employment has varied widely. When jobs unnecessarily require individuals to be a certain height, more women are excluded. This form of "indirect discrimination" is covered in only $5 \%$ of constitutions. When countries allow employers to fire on the basis of pregnancy or childbearing, this affects only women. Ensuring an equal playing field requires recognizing, appreciating, and adapting to these differences, rather than allowing them to provide bases for discrimination.

For the 28 countries that have yet to enact a gender-specific constitutional equality provision, doing so should be a priority. This includes some of the oldest constitutions, which were adopted at a time when women's equal rights were largely ignored. 
There is no reason that older constitutions cannot be amended to explicitly guarantee gender equality; Luxembourg's 2006 revision of its 1868 constitution provides a prime example. After seven years of active efforts, the legislature adopted new language: "Women and men are equal in rights and duties. The State must actively promote the elimination of any existing obstacles to equality between women and men." ${ }^{16}$ The reform process was accelerated by international commitments; early drafts of the provision borrowed language from the Treaty on European Union. ${ }^{17}$ In addition, during its presentations to the CEDAW committee, delegates from other countries urged Luxembourg to hasten its reform process to ensure that the constitution aligned with Luxembourg's international treaty commitments. ${ }^{18}$

In the United States, the revived fight to adopt the Equal Rights Amendment (ERA) has likewise recognized the power of globally contextualizing one's constitution. In a 2018 op-ed, a leading ERA advocate noted that gender equality provisions are "enshrined in most constitutions around the world, and our government has insisted that an equal rights provision be included in the constitutions of other countries, such as Iraq and Afghanistan. Yet this same provision is missing from our own." ${ }^{19}$ Amending centuries-old documents takes political will, and people who want to realize this change in their constitutions must demand their policymakers take action.

For the countries that already have gender-specific protections, in many, they could be strengthened. Most critically, the 14 countries that guarantee gender equality but allow customary or religious law to take precedence over the constitution, including when they do not provide women with equal rights, should remove these exceptions. Countries can also strengthen their constitutions by clearly protecting against indirect gender discrimination - an approach that is missing from 184 constitutions globally. Similarly, protections against pregnancy, marital, and family status discrimination are critical if constitutions are to address some of the most common forms of discrimination that women face in schools, workplaces, and elsewhere. One hundred eighty-two constitutions have yet to prohibit pregnancy discrimination, while 175 are lacking protections against marital or family discrimination.

Finally, constitutions can more comprehensively protect against discrimination by guaranteeing equal rights regardless of both sex and gender. While most constitutions use the word "sex," including "gender" as well provides a stronger foundation for addressing discrimination against people whose appearance, speech, or behavior does not conform to societal expectations of stereotypical male and female roles and characteristics.

\section{One in Thirty: Protecting Fundamental Rights for the World's Migrants and Refugees}

At the time of the drafting of the U.S. and French constitutions, two eighteenthcentury documents that so many countries emulated, movement across vast 
territories and international migration were far more limited. Traveling across the United States took months. No easy routes connected North Africa and France. And even once long-distance journeys became more feasible, discrimination erected high barriers to naturalization, as illustrated acutely when people from China immigrated to California to work in the nineteenth century.

International agreements on the rights of all people grew in number and strength in the twentieth century at the same time that migration for all reasons-economic security, persecution and war, and environmental catastrophesincreased. These included a binding convention specifically on refugees' rights, which has 145 states parties, alongside a treaty on the rights of migrant workers and their families, ratified by 51 countries.

These treaties make clear that refugees and migrants do not relinquish their most fundamental rights upon crossing the border. Specifically, migrant workers' children must have equal access to education as citizens, regardless of their parents' immigration status. Likewise, both agreements protect migrants' and refugees' equal access to health services. With respect to work, the Refugee Convention guarantees that "lawfully staying" refugees-i.e., those who have registered with their host countries' governments-are accorded the same rights to decent working conditions that are granted to citizens. Similarly, the Migrant Workers Convention guarantees that migrant workers receive treatment equal to that of citizens with respect to pay and working conditions.

Yet countries' constitutions have clearly not caught up. Less than one in five guarantee the right to education for noncitizen children. Less than one in six guarantee access to health, while one in five guarantee nondiscrimination at work. This not only leaves migrants behind, but also leaves the 10 million people who find themselves stateless deeply vulnerable to discrimination and exclusion across countries.

Further, even today, racism and religious discrimination infuse immigration policy - a fact laid bare by the Trump administration's so-called "Muslim ban," as well as wide-ranging countries' discriminatory actions over the past five years. In Australia, thousands of refugees and asylum seekers from Asia and the Middle East have been relegated to remote detention centers, drawing comparisons to a set of laws and policies, in place until 1973, that the Australian government later referred to as the "White Australia" policy. ${ }^{20}$ Denmark's government has officially designated 25 low-income, predominantly Muslim immigrant neighborhoods as "ghettos"; beginning at age one, children in these neighborhoods are required to separate from their parents to participate in 25 hours of mandatory instruction in "Danish values" weekly.21

The civil and political rights of racial/ethnic minorities who are citizens are far closer to equal in 2018 than they were in 1970. Yet immigration policies designed to limit racial/ethnic minority populations' growth, and to restrict the rights and success of migrants who are already within country borders, are widespread. Only 
one in four constitutions explicitly prohibit discrimination against foreign citizens without exceptions. For the 151 that do not, banning both discrimination against refugees and migrants and racial/ethnic discrimination must be a priority for ensuring countries do not use race/ethnicity as a criterion for deciding who stays and who goes.

Among the 42 countries that guarantee migrants' rights within their broad equal rights provisions, 19 could further strengthen migrants' and refugees' ability to integrate into new communities and meet their basic needs by ensuring decent working conditions and specific protections from discrimination in education and health. These protections would also better align many countries' constitutions with their commitments under international human rights treaties.

\section{Negotiating the Balance of Religious Freedom and Equal Rights}

Ensuring equal rights for all regardless of religion, belief, or nonbelief comes down to a few principles. First, governments should avoid privileging one religion over other religions, beliefs, or nonbeliefs. Second, governments should ensure strong protections against religious discrimination. And finally, the state should protect freedom of religion for all, up to the point that religious practice conflicts with other people's fundamental rights.

Constitutions are often countries' key instruments for defining the relationship between religion and government-and constitutions around the world have shown it is possible to address all the elements that advance equality. Globally, 14 constitutions take an approach to each of the following: nondiscrimination on the basis of religion; freedom of religion, belief, and nonbelief; limitations on religious practice to protect the rights of others; and no implicit or explicit state privileging of religion.

Many more countries have achieved at least part of this vision. Forty-one percent of constitutions have language committing to the separation of religion and state. Ninety-five percent address freedom of religion, including $41 \%$ describing themselves as secular. Likewise, $25 \%$ protect the freedom to not believe, including $21 \%$ with no state religion or affiliation with a specific religious tradition. Seventyeight percent of constitutions explicitly guarantee equality and nondiscrimination based on religion or belief, including 92\% of those adopted in 2010-17. Forty-six percent of countries note that religious conduct may be limited when it infringes the rights of others.

We also know that religious practice can thrive when these principles are in place and respected. Every major religion can be found thriving in countries that separate religion and state and protect freedom of religion. Further, studies have shown that religious practice fares better in these settings. Countries that protect freedom of religion and have no state religion are less likely to have discriminatory laws that privilege one faith over another, and likelier to support the regular practice of religion. 
At the same time, we have a long way to go to ensure that religious freedom and equality are realized in all countries. Moreover, some evidence indicates governments are becoming more religious, not less, with potential consequences for equality. While constitutions adopted in 2000-2017 are likelier than those adopted before 1970 to identify as secular and have no role for religion (38\% compared to $20 \%$ ), there has also been an increase in established state religions that govern public as well as private life. Among constitutions adopted before 2000, only $7 \%$ established a state religion with control over public life, compared to $26 \%$ of those adopted in 2000-2009 and 21\% adopted in 2010-17.

Overall, 31 countries currently have constitutional provisions limiting equal rights for minority religions. In some, minority religions face unique and explicit restrictions on religious practice. In others, a single religion forms the basis for governance in public and/or family life. Additionally, eight constitutions allow religious law to fully or partly take precedence over the constitution, potentially threatening equal rights not only across religions but on the basis of gender, sexual orientation, race/ethnicity, and other aspects of identity.

Further, among countries that identify as "secular," nearly half nevertheless privilege one religion in other parts of the text. While many of these references likely have more symbolic value than explicit impacts on equal rights, they matter as statements of norms. Especially in an era of growing religious diversity, indirect indications that people of a particular religion or heritage are more welcome than others can undermine full equality.

Given the history of religion-based genocides and massacres, we should all recognize the importance of moving equality forward. It is this history that catalyzed the development of the Universal Declaration of Human Rights (UDHR) and subsequent agreements, including the International Covenant on Economic, Social and Cultural Rights, that clearly protect nondiscrimination on the basis of religion, freedom of belief, and the freedom to practice, subject to others' fundamental rights. The agreements also protect the rights to change religions or forego religion entirely, recognizing that the rights to believe and not believe are two halves of a whole. Most fundamentally, equality across religions and beliefs is about the freedom of thought, which is core to human experience around the world.

The coming decades will likely bring many more constitutional drafting and amendment processes in which the role of religion will be a key issue. Throughout these processes, participants should return to these foundational human rights principles and areas of global consensus as a framework for taking action.

\section{Moving Forward in the Face of Backlash: Equal Rights Regardless of Sexual Orientation and Gender Identity}

Of all the groups we have studied, the LGBT+ community has received the fewest protections from discrimination in national constitutions. Only 11 constitutions 
explicitly protect equal rights on the basis of sexual orientation, while just six also cover gender identity.

Over the past century, constitutional trends have overwhelmingly reflected progress toward equal rights for most groups. With each decade, new constitutions have been increasingly likely to recognize each person's equal worth and humanity regardless of gender, race/ethnicity, religion, or disability. Likewise, older constitutions have adopted amendments recognizing the equality of people of every religion, of men and women, of all racial/ethnic groups, and with and without disabilities.

Recognition of equality across religions began in the mid-180os, followed quickly by recognition across race/ethnicity. It was not until the early 1900 s that equal rights for women began to receive recognition, and these equal rights were protected in a minority of constitutions until the 1960s. Protections for persons with disabilities did not emerge until the 1980 s. $^{22}$ The vast majority of these protections were introduced when new constitutions were adopted, but countries with older constitutions, including Belgium, Chile, France, Greece, Haiti, Luxembourg, Mexico, and Panama, have strengthened equal rights for all through amendments.

But there has not been clear momentum for two groups: migrants and LGBT+ individuals. Even worse, for one group, the rate of constitutions' denial of equal rights has kept pace with protections: although $6 \%$ of constitutions now guarantee equal rights regardless of sexual orientation, another $6 \%$, all adopted or amended since 2000, explicitly prohibit same-sex marriage or allow legislation to do so.

Among the countries where constitutions have guaranteed equal rights on the basis of sexual orientation and/or gender identity (SOGI), public recognition of equality has begun to change. In Mexico, where the constitution newly protected equal rights regardless of sexual orientation through a 2011 amendment, support for same-sex marriage more than doubled from 2000 to $2016 .{ }^{23}$ In South Africa, $37 \%$ of people agreed or strongly agreed that same-sex marriage should be legal in 2015 , compared to just $14 \%$ in 2012; meanwhile, twice as many South Africans believe the constitution should retain its equal rights provision on the basis of sexual orientation as believe it should be removed. ${ }^{24}$

Cases in these countries and others with explicit protections have led to important steps forward, while broad equal rights provisions have provided foundations in some countries without explicit guarantees. Still, at both the national and international levels, much remains to be done to ensure that equal rights on the basis of SOGI are fully protected.

With respect to constitutional protections, the next steps are clear. In 182 countries, newly establishing equal rights on the basis of sexual orientation in the constitution would represent a profound step forward for equality, which could provide the foundation for overturning discriminatory laws and enacting new legislation to ensure comprehensive protections for equality in every sphere. Likewise, in 187 countries, extending protections to gender identity would be 
transformative. Countries should also reform how they describe the right to marry specifically, beginning with the 12 countries that explicitly deny or allow the denial of the right to same-sex marriage. Likewise, the 16 countries that limit constitutional marriage rights to a man and a woman-language that in some countries is a historical holdover, in others a more recent and intentional effort to limit LGBT+ rights-should revise this language to make marriage everyone's right. Countries should also ensure these provisions do not contradict one another. While it is not unusual for countries to experience piecemeal progress toward equality, simultaneously guaranteeing equal rights on the basis of sexual orientation and prohibiting same-sex marriage is an inherent inconsistency that can undermine constitutions' broader legitimacy. Finally, a global treaty specifically protecting the rights of the LGBT+ population is long overdue, and would strengthen efforts to pass critical reforms at the national level.

\section{From Nondiscrimination to Full Inclusion: Guaranteeing the Equal Rights of People with Disabilities}

People with disabilities are the largest group in the world whose equal rights are ignored. An estimated one billion people, or $15 \%$ of the global population, live with disabilities. Yet only a minority of constitutions, $27 \%$, explicitly protect equal rights on the basis of disability, and protections in key areas of life are scarce. Less than one in five constitutions explicitly guarantee a right to education for children with disabilities. Healthcare is essential to all but particularly to the quality of life of people with disabilities, yet less than one in five countries guarantees the right to health services for children and adults with disabilities. The situation is worse with regard to work, where only one in nine countries guarantees nondiscrimination.

True equal rights must include nonsegregation. We have long since stopped accepting the legal segregation of neighborhoods or schools on the basis of race/ethnicity. Yet far too many countries segregate children with disabilities in school, implying that they are different, preventing relationships from forming, and implicitly supporting bias about abilities and value from the earliest ages. Just seven of the world's constitutions include commitments to integration of students with disabilities; in most, these commitments fall short of full inclusion. In some cases, the segregation of children with disabilities may also reinforce racial/ethnic segregation, as discrimination contributes to a higher proportion of children from marginalized racial/ethnic groups being designated as disabled. ${ }^{25}$

Nevertheless, the progress in recent decades, and in particular since the adoption of the Convention of the Rights of People with Disabilities (CRPD) in 2006, is encouraging. Only $12 \%$ of constitutions adopted before 1970 explicitly protect equal rights for people with disabilities; among those adopted between 2010 and $2017,71 \%$ do.

Many of the CRPD's fundamental commitments, including inclusive education and reasonable accommodations in employment, have also been implemented at the national level through legislation. For example, the Americans with Disabilities 
Act (ADA), enacted in 1990 and strengthened in 2008, provides comprehensive standards for how workplaces, schools, public transportation, hotels, stores, and restaurants must ensure accessibility for people with disabilities. Also in 1990, Congress passed the Individuals with Disabilities Education Act, which addressed inclusive education in detail. Over the past several decades, many countries have enacted similar laws.

Yet in many countries, laws are much easier to amend or repeal than constitutional provisions. In the United States, the ADA has been relentlessly attacked in recent years, while shifts on the Supreme Court may further weaken the extent to which persons with disabilities are interpreted as being covered by the constitution's general equality clause. ${ }^{26}$ While ordinary laws may be the best vehicles for spelling out the details of standards like reasonable accommodation and inclusive education, enshrining these same principles explicitly in constitutions can guard against efforts to dismantle legislative protections, while importantly supporting shifts in norms and ensuring basic rights do not erode as the top court's composition evolves. In this way, laws and constitutions play complementary roles in establishing rights and ensuring their enforcement.

For most-141-of the world's countries, explicitly prohibiting discrimination on the basis of disability in the constitution would be a powerful step forward for equal rights. Additionally, 78 countries need to eliminate their constitutional provisions explicitly restricting rights on the basis of disability; many more need to eliminate outdated language and conceptions of disability.

For the 23 countries that broadly guarantee equality for people with disabilities but do not address specific rights, explicit protections against discrimination in education, health, and work-including guarantees of reasonable accommodation in employment and inclusive classrooms-would strengthen constitutional support for equality.

\section{Ensuring Rights and Full Participation Regardless of Social and Economic Position}

Among some of the world's first constitutions, socioeconomic status (SES), and particularly property ownership, dictated whether individuals had access to full citizenship and all associated rights. In 1948, the UDHR proclaimed that fundamental rights and liberties were guaranteed to all, regardless of "social origin, property, birth or other status." Today, however, even as most societies have abandoned rigid social class distinctions, SES discrimination persists. People whose names, appearance, or accents suggest lower-SES backgrounds commonly face discrimination in employment, while poverty more broadly remains stigmatized.

Yet beyond these forms of SES discrimination targeting individuals, when basic healthcare or public education are available only to those with financial resources, these barriers sharply undermine equal opportunity on a broad scale. There is no way a child born into an environment where families cannot afford to send children to school would have the same opportunity as a child born into a wealthy 
home where the cost of education is no barrier-unless there is a guarantee of free education. Clearly, even then, wealth is likely to lead to substantial disparities, but their impact and insurmountability are markedly reduced by the guarantee to all of an affordable quality education.

Compared to other areas of equal rights, relatively few constitutions, 59\%, prohibit SES discrimination. At the same time, these protections appear in $83 \%$ of the constitutions adopted in 2010-17. Where it is not included explicitly in the constitution, some courts, including the U.S. Supreme Court, have held that this type of discrimination receives no special protection.

To better support equal opportunity, the 79 countries that have yet to enact constitutional protections on the basis of SES should do so. Beyond guarantees of nondiscrimination, these protections can include guarantees of access to education and healthcare regardless of income. For example, one in ten constitutions guarantee free medical care for all, while $6 \%$ guarantee the right to medical services specifically for low-income adults and children. In one-third of countries, the constitution guarantees that secondary education will be tuition-free. These are important initial steps for creating an equal playing field.

\section{CROSS-CUTTING ISSUES FOR EQUAL RIGHTS}

Across Part One of this book, some common themes emerged. While explicit protections of equal rights have generally grown for each of the characteristics we examined, none receives protection in all the world's constitutions, and case law has underscored how these omissions matter. In 2013, India's lack of constitutional protection against discrimination on the basis of sexual orientation led the Supreme Court to reinstate a 153-year-old law criminalizing same-sex relationships-a decision that was only overturned five years later based on an expansive reading of the right to privacy and the general equality clause. In the United States, the failure to specifically prohibit SES discrimination led the Court to uphold school financing policies that provided public schools in the poorest neighborhoods with the fewest resources. Although general equal rights protections have produced some transformative victories, their coverage is unpredictable and, in some countries, subject to the interpretations of a handful of judges.

In addition, even when countries have enacted explicit protections, some broader considerations arise about their scope and potential for impact. For example, what about discrimination bridging multiple characteristics? What about discrimination by private-sector employers or private service providers? And if we aim to advance equality not just on paper but in practice, when is prohibiting discrimination inadequate?

\section{Intersectionality}

One challenge for constitutional drafters is whether constitutions and courts can effectively address situations where different types of discrimination intersect and 
overlap. Facets of our identities do not work in isolation; in moving through the world and interacting with institutions and each other, we cannot always separate discrimination based on gender, race/ethnicity, disability, and other characteristics. Yet in the law, these bases of discrimination are generally understood as discrete categories, which often oversimplifies lived experiences of bias and creates a barrier to justice.

For example, if an employer terminates all black female employees but all the black men and white women keep their jobs, a court may find that the fired employees cannot statistically prove either racial discrimination or gender discrimination-even when both are at work. In her seminal article on intersectionality, legal scholar Kimberlé Crenshaw examined a real case involving exactly these facts, DeGraffenreid v. General Motors, in which a district court dismissed five black women's lawsuit against General Motors, finding that "this lawsuit must be examined to see if it states a cause of action for race discrimination, sex discrimination, or alternatively either, but not a combination of both." ${ }^{27}$ As Crenshaw observed, the case revealed how under employment discrimination law, "[b]lack women are protected only to the extent that their experiences coincide with those of [white women and black men]." ${ }^{28}$

Although few constitutions explicitly address intersectionality or related concepts like "multiple" or "cumulative" discrimination, these ideas are receiving greater attention by constitutional courts and the legal community at large-and are increasingly making their way into law. ${ }^{29}$ For example, Spain's Law 3/2007 on Effective Equality between Women and Men calls for particular attention to "cases of double discrimination and to the particular difficulties that women face when in a situation of vulnerability, like women belonging to a minority, migrant women and women with disabilities." ${ }^{\circ}$ Similarly, in a decision about the rights of Aboriginal women, Canada's highest court reasoned that it was essential to "recognize that personal characteristics may overlap or intersect (such as race, band membership, and place of residence in this case), and to reflect changing social phenomena or new or different forms of stereotyping or prejudice." ${ }^{31}$ As courts and constitution drafters continue to wrestle with how to address all forms of discrimination, understanding and identifying strategies to tackle the ways that different forms of bias intersect will be crucial.

\section{Affirmative Measures}

As explored in detail in chapter 2, constitutional provisions that leave the door open to affirmative measures can provide legislatures with important flexibility to address past discrimination, whether on the basis of race/ethnicity, gender, SES, or other grounds. Without acknowledging and addressing the historic policies and practices that led to inequality in the present, there is no way to fully advance equality in the future. A common metaphor illustrates the point clearly: two adults do not have the same chance of crossing a finish line within seven or eight minutes if one begins a half-mile away and the other begins three miles away. In other 
words, equal rights alone do not address disadvantages that preceded the competition or a chance to excel; equal rights alone do not address ongoing sources of disadvantage. Affirmative measures can play important roles in addressing past exclusion and discrimination.

Constitutions should ensure that courts do not automatically consider taking past discrimination into account an equal rights violation; in fact, doing so is often central to advancing equality in practice. Globally, one in six constitutions expressly permit affirmative measures to address histories of discrimination and advance equal rights on the basis of race/ethnicity, as do one in four on the basis of gender.

While policymakers in many countries have struggled with how to most effectively design affirmative measures, experiences from various national settings have offered insights into promising approaches. Considering experiences of discrimination and disadvantage as part of a holistic evaluation, committing to periodic reviews of how policies are working, and targeting the economic and exclusionary impacts of past discrimination can both advance restorative justice and foster more inclusive and representative institutions, with benefits for everyone.

The importance of an intersectional lens also extends to affirmative measures. For example, across numerous countries, past and ongoing racial/ethnic discrimination has created an unequal playing field. Without taking SES into account, though, affirmative measures might primarily benefit individuals who are better off financially and were able to attend better-funded schools, faced fewer financial responsibilities as youth, and had other resource advantages. The issue is not about addressing race, ethnicity, or class-racial/ethnic discrimination and its consequences cut across income levels-but about addressing them together. This also better positions courts and policymakers to focus their efforts on those who have faced the greatest consequences of past discrimination.

\section{Reaching Discrimination in the Private Sphere}

The oldest constitutional protections against discrimination applied only to the government, or to individuals or institutions acting on its behalf. However, private-sector discrimination, both explicit and implicit, substantially contributes to group-based economic disparities and gaps in opportunities. In Brazil, black workers' average wages are half those of their white counterparts. ${ }^{32}$ In Canada, native-born "visible minorities" are lower-paid than white Canadians in privatesector jobs, even though earnings are closer to equal in the public sector. For example, controlling for sociodemographic and human capital variables, black men in private-sector jobs earn $16 \%$ less than their white male colleagues. ${ }^{33}$

In recent years, however, a growing number of countries have begun exploring ways to hold private workplaces accountable under their constitutions. Some countries have done this directly through their constitutional texts. For example, Bolivia's constitution provides: "The State shall ... guarantee [women] the same 
remuneration as men for work of equal value, both in the public and private arena. ${ }^{34}$ Others, such as Colombia, have developed judicial doctrines and procedures that allow individuals to enforce their equal rights against private employers and individuals. In Uganda, the Bill of Rights is expressly applicable against nonstate actors. ${ }^{35}$ While an expansion on the original role of constitutions, addressing private-sector discrimination is integral to the state's responsibility to respect, protect, and fulfill fundamental human rights.

\section{Nondiscrimination and Leveling Up}

Constitutions can also help address private-sector employment inequalities by ensuring that all children, regardless of race/ethnicity, gender, SES, or other factors, have access to a high-quality education, including university, before entering the labor market-an aspect of equal rights that too many countries continue to neglect, despite seminal cases like Brown v. Board of Education condemning racial inequality in the classroom. This example also underscores the important relationship between nondiscrimination and social and economic rights, and why protecting both is important to substantive equality and "leveling up."

For example, if governments respond to prohibitions of racial/ethnic discrimination in education by simply defunding public education rather than desegregating school systems, we have not advanced equality. In the early 1960s, these exact circumstances unfolded in Prince Edward County, Virginia, resulting in nearly 2,000 black students going without public education after a state senator called for "massive resistance" to the Brown ruling. ${ }^{36}$ It was not until a 1964 Supreme Court decision, which found that the students were being denied "their constitutional rights to an education equal to that afforded by the public schools in the other parts of Virginia," that the county was ordered to reopen —and integrate-its public schools. ${ }^{37}$

Unfortunately, the "right to education" in the United States-which is not explicitly protected by the constitution - would not prove to be durable, as detailed in chapter 9. But as the story of the Prince Edward schools underscores, the right to nondiscrimination can only do so much if the government refuses to provide essential public services that are foundational to equal opportunity.

\section{SUMMARY OF FINDINGS: SOCIAL AND ECONOMIC RIGHTS}

In Part Two of this book, we move from nondiscrimination to social and economic rights. Yet although the book's first and second parts address different types of rights, they are deeply intertwined, as the previous section began to elucidate. There is simply no way to achieve equal opportunity without ensuring all people are meeting their basic needs. There is no way two children can have equal opportunities to succeed in school if one is undernourished, arrives hungry, is preoccupied all day by that hunger, and leaves the same. We know this from common 
sense, and from studies demonstrating how much better low-income children perform in school when provided with food. Likewise, there is no way two adults can have equal opportunities to succeed at work or in a profession if one has received extensive education and training and the other has not.

By removing financial barriers to decent healthcare services and an adequate education, while supporting the ability of families to have incomes sufficient to meet basic needs, we can reduce barriers to equal opportunity going forward.

\section{The Right to Education: A Foundation for Equal Opportunities}

The right to education is among the foundational social and economic rights. Education has widespread individual benefits for income, health, employment, and equality, and just as substantial benefits for entire economies. Yet the history of groups' exclusion from education by public and private sectors alike is long. For these reasons, embedding strong commitments to quality, accessible education for all in national constitutions is both an important safeguard for equal rights and a powerful basis for equal opportunities.

Globally, a majority of constitutions- $83 \%$ - protect the right to education, including $53 \%$ that guarantee primary schools will be free. These provisions have played a critical role in advancing the accessibility, affordability, and quality of education in countries around the world. In Colombia and Swaziland, constitutional protections provided the foundation for eliminating tuition fees that led to exclusion. In Indonesia and some U.S. states, constitutional protections for education led to increased government funding for school systems. And in South Africa, constitutional education provisions helped ensure students have the books and desks they need to learn.

Yet with 57 million children still out of school, and persisting gaps in access and attainment across gender, disability, SES, and other factors, much remains to be done. Of the 148 countries that guarantee the right to education, many could strengthen their approach by expanding its scope to keep pace with evolving education standards. Ensuring that the right to education ultimately extends from pre-primary to university would have a transformative impact for both individuals and each of our societies. The 75 countries that currently guarantee only primary can extend these protections to secondary, as Mexico did in 2012. Likewise, the 41 that guarantee only primary and secondary, can consider expanding these protections to include post-secondary education and training.

Affordability is a critical barrier to educational access and attainment. The 47 countries guaranteeing only that primary education is free can support more children to finish their education by establishing that secondary is tuition-free as well. Further, to reduce disadvantages facing particular groups that have historically been excluded from schools and learning opportunities, countries should directly address equal opportunities in education; 122 countries currently take no approach to addressing discrimination within education specifically. 


\section{The Right to Health: From Treatment and Care to Creating the Conditions for a Healthy Life}

Health is foundational to full participation in society and the effective exercise of other fundamental rights. Around the world, constitutional protections for health have produced critical, wide-ranging improvements in people's lives, from expanding access to lifesaving immunizations in Argentina to improving water and sanitation in Bangladesh to increasing access to essential medicines in Peru, Brazil, Costa Rica, and Kenya.

Constitution drafters have increasingly recognized the importance of addressing health. Just one-third of constitutions adopted before 1970 protect a right to health; among those adopted since 2000, 100\% do. Nevertheless, there are still important ways to improve health rights' potential to genuinely improve population health.

First, ensuring that constitutions' and courts' approaches support prevention and health protection, not just treatment after people become sick, will reduce the incidence of illness and injuries and help ensure that resources for health have greater benefits for more people. Measures to make cars, buses, and other transportation safer can save millions of lives and prevent countless more injuries. They also cost countries less than the medical care needed when injuries are not prevented. The same can be said for the millions of preventable deaths due to diarrheal disease, preventable cancer, cardiac conditions, and other causes. People would rather not get sick or injured in the first place-and in countless areas, prevention is far cheaper than treatment. At the same time, a right to medical care is essential: not all illnesses can be prevented, and ensuring access to treatment when sick is fundamental to equal chances in school, work, family, and civic life.

Second, addressing the structural shortcomings of public health and medical systems - rather than solely individual claims that are symptomatic of those flaws - can more dramatically improve the lives of people throughout a country, while ensuring the courts' continued accessibility and efficiency. If thousands of people are approaching the court to seek access to a specific essential medicine, addressing the gaps in their health insurance coverage that put those treatments out of reach would be a more effective and efficient approach than hearing and deciding on each individual claim. In countries that have a "common law" tradition, where prior court decisions are binding on future cases, a series of repetitive claims is less likely, although individuals may also face greater barriers to quickly accessing the courts when their rights are infringed. In "civil law" countries, these circumstances are common. However, courts in civil law countries including Brazil and Colombia have demonstrated the feasibility of calling for more structural solutions.

Ensuring that individuals facing the same legal issue can bring collective claims would advance rights on a broader scale and help prevent backlog in 
court systems. In a range of countries, mechanisms like "public interest litigation" have allowed civil society organizations (CSOs) and public interest lawyers to bring highly impactful cases on behalf of communities and vulnerable groups. Likewise, class action lawsuits have enabled large groups of people to claim their rights to health all at once. These collective approaches have yielded critical victories for child laborers in India, consumers harmed by misleading tobacco marketing in the United States, and people affected by industrial pollution in Bangladesh. ${ }^{38}$

For the 49 countries that do not yet have any constitutional rights to healthor even goals of achieving it-the first step is to take an approach to supporting health promotion, disease and injury prevention, and medical treatment. For the 58 countries that do address medical care but do not clearly address public health or preventive care, doing so could help ensure that the constitution improves the well-being of the largest number of people. Across countries, developing judicial procedures that allow individuals to approach the courts collectively, and courts to issue structural remedies, would further strengthen constitutional health rights' potential to have a transformative impact on people's daily lives and environments.

\section{IS ANYONE PLAYING BY THE RULES?}

For the many countries that do have good rules on the books in at least some areas, is there any evidence that the constitutions matter? Our review of cases from around the world is encouraging. In every area, there are examples of major cases that have transformed whether all people are treated equally by the government, educational and health services, and employers. In Mexico, the Supreme Court was instrumental in establishing equal rights for same-sex couples in practice across the country, building on the constitution's prohibition of discrimination on the basis of sexual orientation. In Brazil, the constitution's commitment to inclusive education prompted the Supreme Court to find that both public and private schools must provide a quality education to students with disabilities. The South African Constitutional Court's decision enabling HIV-positive women to access the treatment necessary to prevent transmitting HIV to their babies, alongside large-scale social mobilization related to the judgment, saved hundreds of thousands of lives. ${ }^{39}$ And in India, Supreme Court rulings have improved urban air quality and reduced children's risk of malnutrition nationwide.

This is not to say there have not also been major cases that have been lost, where equality was diminished, despite the constitution's clarity on the point. Lawyers and judges are human, and courts are imperfect institutions. Any lawyer, whether working to advance equal rights, ensure that governments honor the rights to education and health, protect freedom of speech or association, or encourage the pursuit of environmentally sustainable approaches, will attest that they may lose many cases before winning an important one that proves transformative. 
Our review of cases also illustrates steps that can be taken to increase the likelihood that the values held in constitutions are not just aspirational but lead to improvements in peoples' daily lives. This must include ensuring that all people have straightforward access to the courts and that access to lawyers is affordable. Reforms to the legal system to facilitate individual access must also be accompanied by efforts to remove more informal obstacles, such as language barriers and a distrust of legal institutions previously experienced as punitive rather than empowering..$^{\circ 0}$ Beyond individuals having meaningful access, it is critically important that individual cases can have benefits that extend beyond the individual who brings the case to larger groups.

An active civil society can be instrumental in ensuring that landmark court decisions are actually enforced. Beyond monitoring the implementation of courts' specific orders, civil society groups can play a key role in building on judgments to enact complementary laws and policies. For example, the Right to Food campaign in India, a network of individuals and civil society groups across the country, has played a pivotal role in monitoring enforcement of a series of orders-issued by the Supreme Court since the "right to food" case was heard in 2001-addressing everything from the midday meal program for schoolchildren to a new maternity benefit designed to ensure mothers' adequate nutrition. ${ }^{41}$ The campaign has also led the charge on complementary laws, including 2013's National Food Security Act. In this way, using the constitution in court can be understood as just one piece of a broader strategy for advancing social change.

\section{EVOLVING TOWARD EQUALITY}

In some countries, constitutions embody transformative visions for building a new society. Such constitutions may include guarantees of equality of opportunity that exceed the on-the-ground reality at their time of passage. Other countries have centuries-old constitutions whose core provisions are outdated. In both cases, time and civic engagement will determine whether the constitution will make a meaningful difference for equality. In countries with transformative constitutions, the critical challenge will be implementing and realizing their promises to enable the constitutional visions to reach alignment with lived experiences. In countries with much older constitutions, the challenge will be amending the text to ensure interpretations keep pace with contemporary needs and appreciation of equality.

\section{South Africa: Realizing a Transformative Vision}

South Africa's constitution, which provides an example of the former, was written at a critical period. In the midst of leaving the system of apartheid behind, the majority of people in South Africa were acutely aware of the importance of guaranteeing equal rights to all. The soon-to-be first president, Nelson Mandela, was committed to every minority group having equal rights, even the white Afrikaner 
minority who had developed the system of race-based segregation and oppression. Leaders argued passionately that equal rights would truly be achieved for the large black South African majority who had been denied access to education and health only if the rights to education and health were enshrined in the constitution. As a result, South Africa's constitution embodies an extraordinary vision.

Realizing that vision will take time. Vast educational, housing, health, and economic disparities are not overcome overnight. The Constitutional Court is constrained in the pace at which it can demand change in the spheres of education, health, and housing, which require substantial budgets. Predictably, given the historical context, full participation in the political system is still emerging. In most countries, democratic institutions take years to fully and successfully emerge when they have previously been suppressed.

Still, the South African Constitution's accomplishments are truly remarkable. In addition to taking a major stride forward on preventing mother-to-child HIV transmission, the Constitutional Court has served as a global example in other areas of equal rights. In a 1994 case based on the interim constitution, the Court's ruling that asylum seekers could not be excluded from receiving public education or seeking work is estimated to have impacted over 50,000 individuals, all of whom were socioeconomically disadvantaged. ${ }^{42}$ In a series of rulings on education, the Court has strengthened the constitutional commitment to quality, inclusive education for all students, and the end of segregation. And its 2005 ruling on same-sex marriage made South Africa the first African country to guarantee marriage equality.

\section{United States: Cultivating Protections for Equality over Time}

Similarly, though its constitution is centuries older, realizing equal constitutional rights in the United States has been a long-and ongoing-process. As drafted exclusively by a group of white, male property owners in the eighteenth century, the U.S. Constitution guaranteed rights to the few, not the many. Following the Civil War, the constitution's potential to advance equality increased immensely, with the Thirteenth Amendment's prohibition of slavery, the Fourteenth Amendment's establishment of the Equal Protection Clause, and the Fifteenth Amendment's extension of the right to vote to freed male slaves.

These provisions took on new life during the Civil Rights Movement, providing tools for dismantling Jim Crow and dispensing with the idea that "separate but equal" could be compatible with true equality. In Brown v. Board of Education, the Supreme Court ruled in 1954 that segregated public schools were unconstitutional. That same year, the Court ruled for the first time, in Hernandez v. Texas, that the Equal Protection Clause applied to Mexican Americans, reasoning that it should extend beyond distinctions between white and black Americans to any instance in which a particular group of people was singled out for differential treatment. In 1960, the Court held in Gomillion v. Lightfoot that the redrawing of city boundaries 
in Tuskegee, Alabama, into a 28-sided shape that would exclude virtually all black voters was unconstitutional under the Fifteenth Amendment. And in 1967, in Loving v. Virginia, the Court found that state laws prohibiting interracial marriage violated the Equal Protection Clause.

Civil rights lawyers also drew on both the Fourteenth Amendment and other constitutional provisions to expand the reach of antidiscrimination laws to the private sphere. In Shelley v. Kraemer, in 1948, the Supreme Court held that the Equal Protection Clause prohibited the enforcement of real estate covenants that banned black people from purchasing homes. Even though the constitution did not apply to private contracts, the Court ruled, courts' enforcement of discriminatory contracts would amount to "state action" prohibited by the Fourteenth Amendment. In 1964, the Court ruled in Heart of Atlanta Motel v. United States that the Civil Rights Act of 1964, which prohibited discrimination by privately owned hotels, restaurants, and other public accommodations, was a valid exercise of Congress's constitutional authority to regulate interstate commerce. The Court reached the same conclusion in Katzenbach v. McClung, ruling against an Alabama restaurant owner who refused to serve black customers, arguing that the Civil Rights Act was unconstitutional.

Despite generations of progress, however, the U.S. has far to go toward realizing the ideals that many Americans believe the constitution represents. While the Equal Protection Clause was a critical step forward, courts and legislatures have still done too little to address the enduring economic impacts of centuries of racial exclusion created by law. For nearly four decades, an amendment to guarantee equal rights to women has languished in the state legislatures, although its momentum began rebuilding in 2017. While court rulings and legislative reforms have critically advanced equal rights for people with disabilities and the LGBT+ community, the lack of explicit protections for either group in the constitution puts rights at risk as politics shift and the Supreme Court's composition evolves. The U.S. Constitution is also now one of the few in the world that fail to guarantee fundamental social and economic rights, and vast inequalities in access to quality education and healthcare underscore the consequences of this neglect.

Across constitutions new and old, fully realizing rights takes time. It also takes continued engagement by people who care about ensuring that their constitution genuinely reflects our shared values and priorities. But when these rights on paper become reality on the ground, the impact on individual lives and communities can be profound. 